\title{
Hepatotoxicity of herbal and dietary supplements: an update
}

\author{
Felix Stickel · Daniel Shouval
}

Received: 23 December 2014 / Accepted: 5 February 2015 / Published online: 14 February 2015

(C) Springer-Verlag Berlin Heidelberg 2015

\begin{abstract}
Herbal and dietary supplements (HDS) have been used for health-related purposes since more than 5000 years, and their application is firmly anchored in all societies worldwide. Over last decades, a remarkable renaissance in the use of HDS can be noticed in affluent societies for manifold reasons. HDS are forms of complementary and alternative medicines commonly used to prevent or treat diseases, or simply as a health tonic. Another growing indication for HDS is their alleged benefit for weight loss or to increase physical fitness. Access is easy via internet and mail-order pharmacies, and their turnover reaches billions of dollars in the USA and Europe alone. However, HDS are generally not categorized as drugs and thus less strictly regulated in most countries. As a result, scientific evidence proving their beneficial effects is mostly lacking, although some HDS may have purported benefits. However, the majority lacks such proof of value, and their use is predominantly based on belief and hope. In addition to missing scientific evidence supporting their use, HDS are typically prone to batch-to-batch variability in composition and concentration, contamination, and purposeful adulteration. Moreover, numerous examples of preparations emerged which have been linked to significant liver injury. These include single ingredients, such as kava, germander,
\end{abstract}

\section{F. Stickel}

Department of Gastroenterology and Hepatology, University Hospital of Zürich, Zürich, Switzerland

F. Stickel $(\bowtie)$

Division of Hepatology, Clinic Beau-Site, Hirslanden Bern, Switzerland

e-mail: felix.stickel@hirslanden.ch

D. Shouval

Liver Unit, Institute for Gastroenterology and Hepatology,

Hadassah-Hebrew University Hospital, Jerusalem, Israel and several Chinese herbals. Other HDS products associated with liver toxicity consist of multiple, often ill-defined ingredients, such as Hydroxycut and Herbalife. Affirmative diagnostic tests are not available, and the assessment of liver injury ascribed to HDS depends on a thorough and proactive medical history, careful exclusion of other causes, and a search for available reports on similar events linked to the intake of the suspected preparation or ingredients contained therein.

Keywords Complementary medicine $\cdot$ Drug-induced liver injury · Hepatitis · Liver failure

\section{Introduction}

Despite the progress of mainstream medicine in the last decades, a stupendous increase in the popularity of herbal and dietary supplements (HDS) has been recorded. A national telephone survey in the USA first undertaken in 1990 demonstrated a sharp rise in the consumption of HDS from 2.5 to $12.1 \%$ in 1997 when the interview was repeated (Eisenberg et al. 1993, 1998). Similar figures exist for Europe where the use of herbals varies considerably between studies, but outscores all other complementary medicine approaches (Posadzki et al. 2013; Eardley et al. 2012). Marignani and colleagues investigated the proportion of patients with hepatobiliary disorders taking HDS and patients' attitudes toward such interventions and found more than one-third of subjects admitting the use of HDS, often complementary to conventional medication (Marignani et al. 2010). Even higher figures were found in an inquiry within six liver disease clinics across the USA which revealed that up to $65 \%$ of patients with liver disease take HDS (Strader et al. 2002). Many factors contribute to 
herbal medicine's appeal. A positive aspect may be that it reflects an increased awareness toward health and wellbeing in general, but the expectations toward the purported virtues of HDS are as numerous as the diverse groups of users. In declining order of prevalence, they included hope to influence the natural history of a given disease, disease prevention and the promotion of health/general well-being, reduction of side effects of other drugs, retain control over one's health, improvement of symptoms, boosting the immune system, emotional support, holistic care, improving quality of life, good therapeutic relationship, obtaining information, coping better with illness, supporting the natural healing process, and availability of treatment (Ernst and Hung 2011). These motivations reflect a deep belief that HDS are safe because they are "natural," and fit into the image of a gentle and, therefore, harmless alternative to conventional medicine. Even more so, patients are often dissatisfied with the latter because of suboptimal treatment success or adverse effects. In addition, HDS are usually excluded from tight prescription regulations and thus can be easily purchased in pharmacies, health stores, gyms, and more recently from internet sources, and are relatively inexpensive.

Although there is vague evidence for efficacy of most HDS, there is unquestionable proof that such agents are sometimes responsible for causing liver injury, very much in contrast to the belief of users. Hepatotoxicity caused by complementary and alternative medicines was one of the two most common etiologies reported among 24,112 Chinese patients with DILI (Zhou et al. 2013). A tabular compilation of the numerous case reports on herbs and herbal products associated with hepatotoxicity can be found in (Teschke et al. 2012) and in Table 1. In the absence of regulatory guidelines, the true incidence of hepatotoxicity from HDS is not known. Published evidence predominantly relies on sporadic reporting, and proper pharmacovigilance-such as with synthetic drugs-is not in place. The widespread use of HDS is largely uncontrolled, and unawareness of consumers and healthcare providers toward their potential dangers likely causes significant under-reporting. A relatively low proportion of $2 \%$ of cases of DILI in a Spanish report was ascribed to HDS (García-Cortés et al. 2008), whereas the US Drug-Induced Liver Injury Network (DILIN) found $10 \%$ of cases attributable to HDS (Chalasani et al. 2008). A more recent study by the same DILIN investigators scrutinized hepatotoxicity from HDS and its outcomes versus that of conventional medications among patients enrolled between 2004 and 2013. Among the 839 patients recruited with DILI, $130(15.5 \%)$ were judged to have experienced liver injury due to HDS. Liver injury due to HDS increased from 7 to $20 \%(p<0.001)$ during the study period and more frequently led to death or transplantation compared to injury from conventional medications (13 vs. $3 \%$, $p<0.05$ ) (Navarro et al. 2014). The latter observation fits to data from two small series of patients progressing to hepatic failure. These include 20 US patients with liver failure of whom $35 \%$ were considered the result of HDS intake (Estes et al. 2003), and 30 patients from China all of whom diagnosed with acute liver failure associated with intake of traditional Chinese medicines (Zhao et al. 2014).

In the light of these data, the present review provides an updated summary on the topic to emphasize the possibility of HDS as a potential cause of liver injury, and guidance on how to manage a clinical case in which this is suspected.

\section{Diagnostic and causality assessment of HDS-associated liver injury}

Awareness toward liver injury from conventional drugs is well rooted among most medical professionals, whereas HDS as a potential etiology has only recently been recognized, although they may present with the same spectrum of liver pathologies as synthetic products. Diagnosis isas with conventional medication-difficult and requires a significant degree of suspicion from the assessor, but clinicians often do not think of HDS as a potential cause of liver damage, and thus fail to inquire their use. In addition, willingness of patients to be forthcoming about the use of such products is low, either because they do not consider them potentially harmful, or because they fear not to be taken seriously by the physician. Thus, in many published reports, herbals are only classified as the true cause after repeated questioning. No specific diagnostic test or biomarker is available to either rule out or confirm causality, and assignment to a specific HDS ensues via exclusion of other causes. Causality assessment, the process of determining whether there is a reasonable likelihood that a drug or HDS is the cause of liver injury, is performed generally using one of several assessment methods (Maria and Victorino 1997; Aithal et al. 2000; Rochon et al. 2008). Determination of causality of toxicity for HDS in general and for herbal hepatotoxicity in particular is usually not an easy task and especially when such agents contain several ingredients with an origin which is not always easy to trace. Regardless of these limitations, such methods have been employed for determining causality for liver injury of conventional medications as well as of HDS, but there has not been a distinctive or formal method developed to assess causality for liver injury attributable to HDS. Importantly, the assessment must be conducted in a carefully defined and methodical fashion (Fig. 1). 


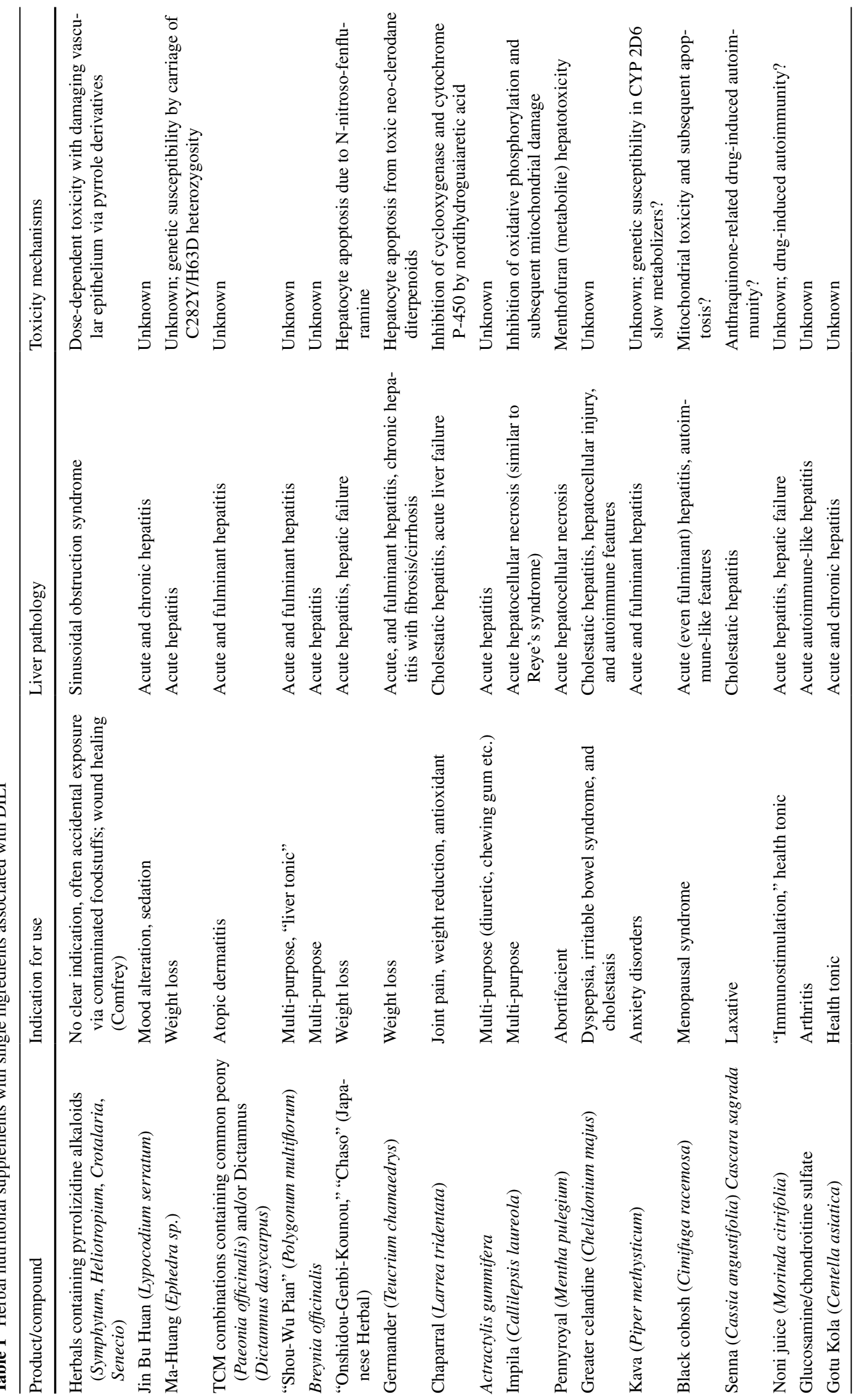




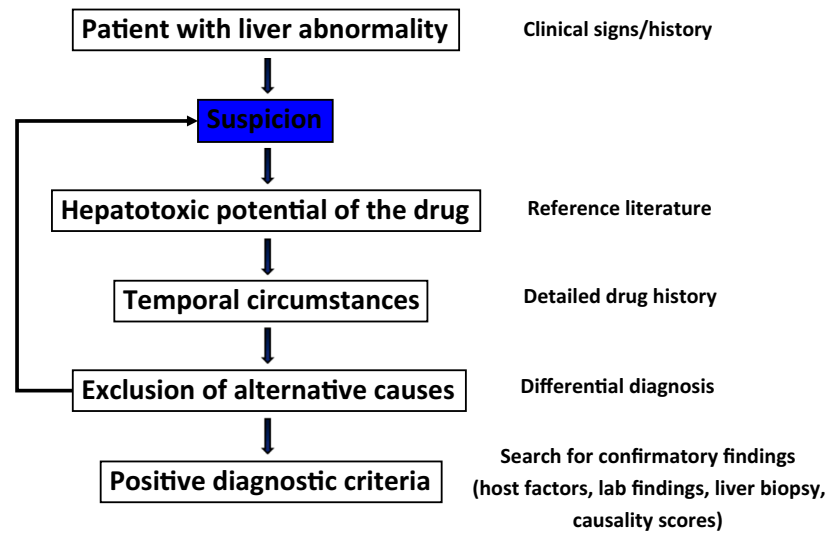

Fig. 1 Establishing causality in DILI due to HDS is complex and involves a high degree of suspicion and searching of the literature. No confirmatory tests are available, and diagnosis is often made by exclusion of other non-DILI causes of liver abnormalities. Useful are causality scores established for DILI due to synthetic drugs

\section{Quality and safety assurance of herbal products}

The rapidly expanding use of herbal products and especially those used as HDS has put quality and safety assurance of such compounds in the focus of attention of the scientific community and regulatory authorities worldwide (Chang 1999; Fu et al. 2009; Vlietinck et al. 2009; Goodarzi 2013; Alaerts et al. 2014; Regev 2014; Deconinck et al. 2015). Good agricultural practice (GAP) and good manufacturing practice (GMP) guidelines and use of reference reagents should be the corner stones for standardization of manufacturing of HDS. However, regulatory control using such procedures is still not enforced universally. Chromatographic techniques are available to assess the quality of individual herbs and to screen for adulterants. Yet, interpretation of results obtained through such procedures is often difficult, especially when testing large mixtures of herbs and pharmacologic agents which may also interact among themselves. It has been suggested that in case of an investigation regarding potential hepatotoxicity of a particular product, the minimal information used for quality assurance should include: identification of the manufacturer's address, phone and fax number, as well as email address; expiration date of the product; batch number; detailed recommendations for indications and contraindication; daily dose and maximum duration; correct labeling of all ingredients; accurate definition of plant family and plant part; definition of solvents, solubilizers, and excipients; assurance for consistency from batch to batch as well as regulatory approval. Regretfully, such information is often unavailable to the investigator. The EU has recently proposed a simplified procedure allowing the registration of herbal medicinal products. Thus, the quality and safety of herbal products will be determined by employment of agreed upon analytical procedures published in the European Pharmacopoeia and supervised by the European Medicines Agency (EMEA) (Vlietinck et al. 2009). The current regulatory status of herbal products in the USA, Canada, the UK, and some Asian countries is reviewed in reference (Seeff et al. 2014).

\section{HDS associated with liver injury}

HDS may cause liver injury similar to that attributed to conventional synthetic drugs, and clinical presentation can be highly variable, even with the same product. Likewise, there is no recognized uniform mechanism by which liver injury is precipitated, and predisposing risk factors are identified for only a minority of preparations. Due to these similarities, clinical signs and laboratory findings are often falsely ascribed to other putative hepatotoxic drug before HDS or self-prepared herbals are suspected. Pivotal to correctly diagnosing HDS as the underlying cause of DILI is the investigator's awareness and suspicion leading to a thorough drug history with specific interrogation for the intake of "natural," "herbal," or unconventional medication. No specific laboratory tests are available to prove or rule out HDS (and most synthetic drugs) as the cause of liver injury. Performing a liver biopsy may be justified, but histopathology reports often turn out to be at best "compatible" with DILI, which does not aid to dissect conventional drugs from herbals as the cause of DILI.

The following description is a brief summary of HDS associated with DILI according to the literature to date. For a better structure, we deliberately separated herbals from dietary supplements although both sometimes overlap. Evidence in most cases is based on single of series of case reports, and systematic cross-sectional, population-based, or even prospective studies are rare. An overview of herbals and defined HDS that have been associated with liver damage is provided in Table 2. Regular updates on drugs or xenobiotics associated with liver damage can be found on internet-accessible Web sites (http://livertox.nih.gov/; Zhu and Kruhlak 2014).

Herbals containing pyrrolizidine alkaloids

Several thousands of cases of pyrrolizidine alkaloid (PA)induced cases of liver injury have been reported worldwide (Lin et al. 2011). Pyrrolizidine alkaloids (PAs) such as symphytine, echimidine, seneciophylline, retronescine, and monocrotaline are contained in extracts from common heliotrope (Heliotropium), ragwort (Senecio), comfrey (Symphytum officinale), Crotalaria species, and the Chinese medicine 'Tusanqi' (Gynura segetum) to name only a few examples. While comfrey is used as the active ingredient 
Table 2 Herbal nutritional supplements associated with DILI

\begin{tabular}{|c|c|c|c|}
\hline Product/compound & Indication for use & Liver pathology & Toxicity mechanisms \\
\hline Several Herbalife ${ }^{\circledR}$ combinations & $\begin{array}{l}\text { Various (weight loss, nutritional } \\
\text { support, "well-being") }\end{array}$ & $\begin{array}{l}\text { Variable (acute and chronic hepati- } \\
\text { tis, cholestasis, cirrhosis, and } \\
\text { hepatic failure) }\end{array}$ & $\begin{array}{l}\text { Unknown; autoimmunity? Bacterial } \\
\text { contamination? }\end{array}$ \\
\hline Usnic acid (e.g. LipoKinetix ${ }^{\circledR}$ ) & Weight loss & Acute hepatitis & Uncoupling of respiratory chain? \\
\hline Hydroxycut & Weight loss & $\begin{array}{l}\text { Acute and/or cholestatic hepatitis, } \\
\text { liver failure }\end{array}$ & Unknown \\
\hline Anabolic steroids & Sports performance, doping & $\begin{array}{l}\text { Cholestasis, steatosis, and peliosis } \\
\text { hepatis }\end{array}$ & $\begin{array}{l}\text { Inhibition of biliary transporter } \\
\text { proteins }\end{array}$ \\
\hline Green tea (Camellia sinensis) & Weight loss & Acute hepatitis & $\begin{array}{l}\text { Oxidative stress from (-)-epigal- } \\
\text { locatechin gallate? }\end{array}$ \\
\hline Oxy Elite Pro & $\begin{array}{l}\text { Weight loss, improvement of } \\
\text { physical performance }\end{array}$ & Acute and fulminant hepatitis & Unknown \\
\hline
\end{tabular}

of commercial tinctures and ointments available in pharmacy shops to treat bruises and joint injuries, while oral PA preparations are banned in Europe and Northern America. Exposure of humans to other PA-containing herbals rather occurs via contaminated foodstuff such as salads, cereals, and even honey, or and only rarely by therapeutic intention (Prakash et al. 1999).

A clinical syndrome described as 'Senecio disease' in South Africa including ascites, hepatomegaly, and cirrhosis in some patients (Wilmot and Robertson 1920), and reports of cases from Jamaica about children presenting similar symptoms after the ingestion of 'bush tea' made from Crotalaria (Bras et al. 1954) are among the earliest reports. Contamination of gondli, a wide-used crop with Heliotropium, was the reason for remarkable series of PA intoxications in India (Tandon et al. 1976) and Afghanistan (Kakar et al. 2010). In Western countries, several reports, some of which in infants, describe serious liver damage after the consumption of herbal tea made of ragwort (Senecio longilobus) and Alpendost (Adenostyles alliariae) (Stillman et al. 1977; Sperl et al. 1995). A hitherto undescribed syndrome termed Hirmi Valley liver disease was first reported in 2001 in Tigray, Ethiopia, with 591 cases of which 228 died (Robinson et al. 2014). Clinical presentation included abdominal pain and distension due to ascites, bloody diarrhea, and hepatosplenomegaly. Liver injury was ascribed to the PA acetyllycopsamine detected in stored grain, which in combination with the pesticide DDT (dichlorodiphenyldichloroethylene) produced either acute injury characterized by centrilobular necrosis or chronic injury with bile ductular reaction, cytomegaly, and fibrosis.

PA exerts a clear dose-dependent hepatotoxicity, and the characteristic type of liver injury provoked by PA is sinusoidal obstructive syndrome (SOS), previously referred to as veno-occlusive disease. In SOS, a non-thrombotic obliteration of the lumen of the terminal centrilobular hepatic veins results in venous outflow obstruction, consecutive hepatic congestion, and parenchymal necrosis. However, some PA may also cause hepatocellular necrosis without vascular lesions (Robinson et al. 2014). Clinical presentation can be either acute up to fulminant liver failure or chronic with progressive liver fibrosis and cirrhosis and the majority of patients reveal ascites (DeLeve et al. 2002). Imaging tests with computed tomography or magnetic resonance tomography can be variable with patchy liver enhancement and main right hepatic vein narrowing or occlusion (Zhou et al. 2014). However, SOS can also present as a liver mass mimicking a primary or secondary hepatic malignancy ( $\mathrm{Ng}$ et al. 2014). Treatment of affected patients is symptomatic, and after cessation of PA intake, spontaneous recovery PA is possible. Injury occurs due to direct toxic effects from PA transformed into pyrrole derivatives by microsomal P450 enzymes (Mei et al. 2010), and inducers of cytochrome P450 3A4, 2B6, and several isoenzymes of the $2 \mathrm{C}$ family may enhance PA toxicity. Acute toxicity is not species specific, and an animal model of SOS using monocrotaline has been characterized (DeLeve et al. 1999).

Chinese herbs

Herbal medicine as part of traditional Chinese medicine (TCM) dates back as far as 2100 B.C., and the rising popularity of oriental medicines in general has promoted its use worldwide. Traditionally, most Chinese medicines are mixtures of several different herbs of which one or two are considered the pharmacologically active "King herbs,"while the remaining constituents are intended to modulate the effect of the King herb, alleviate its toxicity, or support circumstances considered important for regaining health. More than 13,000 different herbals preparations are used in TCM which makes it extremely difficult to scientifically identify the active component or the ingredient responsible for the liver injury. Active or toxic ingredients may 
vary when plants are harvested during different seasons or extracted through variable procedures. Also, contamination of herbals with microorganisms, pesticides, heavy metals, fungal toxins such as aflatoxin, and synthetic drugs has been described (Efferth and Kaina 2011).

The Chinese herb Jin Bu Huan extracted from Lypocodium serratum (Creeping Cedar) was widely used in the USA during the 1990s for mild sedative effects. During that time, a total of 11 cases of both acute and chronic hepatitis (Woolf et al. 1994; Piciotto et al. 1998) and several reports of cardiorespiratory misadventures were published (Horowitz et al. 1996). Liver enzyme elevations normalized upon discontinuation of treatment. While the sedative properties are due to laevo-tetrahydropalmatine which harbors opiate-like properties, the toxic mechanism by which liver injury is precipitated remains unknown. Laevo-tetrahydropalmatine shares structural similarities to PA; however, liver histology from Jin Bu Huan typically shows focal necrosis and portal fibrosis, but no features of SOS.

A number of HDS marketed for weight loss in the USA contained Ma-Huang (Ephedra sp.). Besides cardiotoxicity, several published incidents demonstrated as risk of hepatotoxicity from Ma-Huang with acute hepatitis quickly after intake, sometimes with elevated autoantibodies, suggesting drug-induced autoimmunity (Nadir et al. 1996; Neff et al. 2004; Vigano et al. 2008). Another series showed an association of Ma-Huang hepatotoxicity with genotype C282Y/ H63D within the HFE gene, but this link has not been confirmed (Bajaj et al. 2003).

Several cases of acute hepatitis and even fulminant hepatic failure with a fatal course in two subjects were reported from studies investigating the efficacy of combinations of several Chinese herbals used to treat atopic dermatitis (Kane et al. 1995; Yoshida et al. 1996; McRae et al. 2002). The majority of used combinations contained common peony (Paeonia officinalis) and/or Dictamnus (Dictamnus dasycarpus), but the causative component remained unclear. Regarding the latter, a single series of four cases of acute hepatitis was reported from Korea commencing after the intake of a decoction made by boiling down the root of Dictamnus dasycarpus. Liver injury subsided in all cases after cessation of intake (Jang et al. 2008).

A remedy formulated from the roots and vines of Polygonum multiflorum, termed "Shou-Wu Pian," is used as a treatment for dizziness, hair loss, constipation, and interestingly, as a "liver tonic.". Since the first report on a case of acute hepatitis in a 31-year-old pregnant woman in 1996 (But et al. 1996), numerous larger series of cases confirmed its potential to cause liver injury including liver failure mainly in China and Korea where "Shou-Wu Pian" is used manifold as an antiaging tonic to treat tinnitus and to prevent premature greying of hair, lumbago, and constipation (But et al. 1996; Park et al. 2001; Mazzanti et al. 2004;
Panis et al. 2005; Cárdenas et al. 2006; Laird et al. 1998; Jung et al. 2011; Dong et al. 2014; Ma et al. 2014). It has been speculated that toxicity may be related to anthraquinones, which are known constituents of Polygonum multiflorum, but this hypothesis has not been proven.

Breynia officinalis, a species of Euphorbiaceae, has long tradition in China as a treatment of contusions and bruises, heart failure, venereal diseases, growth retardation, and conjunctivitis, sometimes in combination with other traditional Chinese herbals. The first cases of liver injury from this herbal were identified in Taiwan involving two women with acute cytolytic hepatitis (Lin et al. 2002), followed by a larger series of 19 poisonings which occurred after the consumption of a soup cooked with Breynia officinalis, accidentally mistaken for a similar plant, Securinega suffruticosa (Lin et al. 2003). No cases outside Taiwan have been reported to date.

\section{Germander}

A prominent example of a HDS approved as a weight loss remedies is germander (Teucrium chamaedrys) which was licensed and distributed as capsules and tea bag preparations in France in the early 1990 s. Numerous reports to the French pharmacovigilance authorities in 1992 about germander-associated acute, chronic, and even fulminant hepatitis (Larrey et al. 1992) were recorded. Typically, liver injury presented as acute cytolytic hepatitis, but some patients with a chronic course of liver disease were also recorded revealing histologic features of chronic hepatitis with fibrosis and even cirrhosis. Causality assessment linking germander and liver damage is undisputed after several incidents of accidental re-exposure followed by immediate relapse of liver injury. However, all patients recovered after discontinuation of the herbal except for those with cirrhosis. French pharmacovigilance authorities banned germander products and no further cases were recorded. However, two recent cases were recorded in Italy of a married couple who developed acute hepatitis after ingesting a self-made decoction containing $T$. chamaedrys L., with proven causality after voluntary re-exposure (Gori et al. 2011).

For germander, rigorous research of toxicity in animal studies identified furane-containing neo-clerodane diterpenoids as the precipitating compounds (Loeper et al. 1994; Kouzi et al. 1994; Lekehal et al. 1996; Fau et al. 1997). Formation of epoxides is enhanced by induction of cytochrome P450 3A and by glutathione depletion, which may occur during weight loss or regular alcohol consumption. In France, all preparations containing T. chamaedrys L. as herbal medicine are revocated, while the US. Food and Drug Administration permits T. chamaedrys L. extracts at low levels in alcoholic beverages only. 
Another member of the Teucrium labiatae, T. polium (Felty Germander or Hulwort), has been shown to cause fulminant hepatic failure following its ingestion as an antiinflammatory and antimicrobial drug and for the treatment of scars (Mattei et al. 1995; Savvidou et al. 2007). There is also a single report of acute hepatitis with jaundice that occurred in a patient who took a traditional Chinese remedy containing Teucrium viscidum for back pain that resolved spontaneously after the remedy had been stopped (Poon et al. 2008).

\section{Chapparal}

Chaparral (Larrea tridentata) is a traditional herbal remedy among Native Americans who refer to it as Creosote Bush or Greasewood to treat common cold, bone and muscle pain, and snake bites. Like with many herbals once adopted by Western societies, commercial products containing Chaparral were mainly sold for alleged weight-reducing properties, and for presumed anti-inflammatory, antioxidant and "blood-purifying" benefits. Furthermore, patients with human immunodeficiency virus infection turned to Chaparral as part of their adjuvant self-medication (Kassler et al. 1991). In the 1990s, the FDA recorded a series of cases of Chaparral-related hepatotoxicity ranging from mild elevations of serum liver enzyme concentrations to fulminant hepatitis with subsequent liver transplantation for hepatic failure in two cases (Sheikh et al. 1997). Although cholestatic hepatitis accounted for the majority of cases, there were also chronic sequels with cirrhosis. Larrea tridentata was found in all preparations, and biochemical and microbial contamination was excluded. A causal relationship was postulated based on the temporal correlation between intake of Chaparral and the onset of liver disease, a consistent pattern of hepatic damage, and through the observation that reexposure to Chaparral or an increased in its dose led to relapse or aggravation of clinical signs of liver disease. While the magnitude of cases was noticed in Northern America, Kauma and coauthors described a case of a previously healthy woman in Finland who developed severe acute hepatitis after the intake of chaparral tablets (Kauma et al. 2004). Chaparral toxicity is likely due to nordihydroguaiaretic acid which inhibits cyclooxygenase and cytochrome P-450 (Agarwal et al. 1991).

\section{Actractylis gummifera and Callilepsis laureola}

Extracts of A. gummifera have been used traditionally as a natural antipyretic, emetic, diuretic and as chewing gum by children in North Africa and the Mediterranean. Sometimes, ingestion occurs when A. gummifera is confused with wild artichoke, and cutaneous application also appears to carry a risk of inducing liver injury (Bouziri et al. 2010).
Acute onset of toxic hepatitis with potentially fatal hepatorenal failure is well described and associated with severe neurovegetative symptoms and pronounced hypoglycemia (Georgiou et al. 1988; Hamouda and Hédhili 2004). Sporadic cases are still occasionally recorded until recently advocating the demand for education on the potential risks of using A. gummifera (Mouaffak et al. 2013). Consumption of A. gummifera is particularly dangerous during spring time when toxins are highly concentrated in roots.

A traditional herbal remedy used among the Zulu people in South Africa is called Impila which contains Callilepsis laureola as the major constituent. Impila is the Zulu word for "health" and is used as a multi-purpose treatment for stomach problems, impotence, infertility, and to deter "evil spirits." However, a series of incidents substantiate evidence for potentially lethal nephro- and hepatotoxicity of C. laureola (Popat et al. 2001). Particularly, worrisome is a large series of children identified retrospectively as having died from $C$. laureola intoxication who presented with a clinical picture similar to Reye's syndrome with acute hepatorenal failure, hypoglycemia, and multi-organ bleeding (Watson et al. 1979). Autopsy examinations showed centrilobular zonal necrosis of the liver, tubular renal necrosis, and hemorrhages in lungs, skin, and intestine. Despite its well-known toxicity, the underlying mechanism is only partly understood. Animal studies in rats indicate that atractyloside and carboxy-atractyloside are potent inhibitors of oxidative phosphorylation and other mitochondrial functions, which may lead to uncoupling of the respiratory chain and subsequent apoptosis (Stewart et al. 2002). Popat et al. (2002) have shown that Impila extracts cause a concentration- and time-dependent loss in cell viability and mitochondrial glutathione (GSH) content in HepG2 cells preventable with $\mathrm{N}$-acetylcysteine and S-adenosyl-L-methionine, precursors of GSH. Whether treatment of intoxicated subjects is beneficial, is unknown until know, and novel cases of Impila intoxication have not been published for the past 15 years.

\section{Pennyroyal}

A relatively rare cause of liver damage is that associated with Pennyroyal, also referred to as "squawmint oil." Its traditional use is as a natural abortifacient and deterrent against fleas. Pennyroyal is made of leaves from either Mentha pulegium or Hedeoma pulegoides and has long been identified as a cause of severe acute liver injury (Poon et al. 2008). Several reports of fulminant hepatic necrosis due to Pennyroyal with lethal outcome have been described (Sullivan et al. 1979; Anderson et al. 1996). Its primary constituents are pulegone and various other monoterpenes characteristically contained in mint species. Hepatotoxicity appears to be due to depletion of GSH by pulegone, 
consecutive enhanced oxidative stress, and via pulegone's primary metabolite menthofuran which is transformed through cytochrome P450 into a hepatotoxin (Bakerink et al. 1996; Thomassen et al. 1990; Thomassen and Knebel 1992; Gordon et al. 1987).

\section{Greater chelandine}

Preparations containing greater celandine (Chelidonium majus) were widely used in Europe to improve bile flow and in the treatment of irritable bowel syndrome although the clinical evidence supporting its use for these indications was far from robust. Greater celandine contains at least 20 different alkaloids including berberine, coptisine, chelerythrine, and chelidonine, of which the latter compound is measured to standardize the extract. Several reports from European countries have described its potential to precipitate liver injury (Benninger et al. 1999; Crijns et al. 2002; Stickel et al. 2003; Hardeman et al. 2008; Moro et al. 2009). The largest series of 10 patients revealed cholestatic hepatitis together with low titers of autoantibodies suggesting drug-induced autoimmunity after variable periods of ingestion of different greater celandine preparations (Benninger et al. 1999). However, the exact mechanism responsible for injury remains unclear and efforts to develop an animal model have thus far failed. With effect of April 9, 2008, approval of all preparations containing more than $2.5 \mathrm{mg}$ of chelidonine was revocated in Germany. Up to 2011, 124 cases of adverse hepatic reactions associated with the use of greater celandine had been reported to the Vigisearch database of the World Health Organisation in Uppsala. As a consequence, the Herbal Medicinal Products Committee (HMPC) of the European Medicines Agency (EMA) released a public statement on the use and safety of Chelidonium majus and concluded "...that evidence of clinical efficacy was lacking for monotherapy and thus a well-established use indication was not supported. The HMPC considered the documented traditional uses for Chelidonium majus, but concluded that in the presence of a high number of spontaneously reported hepatobiliary adverse drug reactions and the withdrawal of products in Member States due to safety concerns, the benefit-risk assessment of oral use of Chelidonium majus is considered negative..." (http://www.ema.europa.eu/docs/en_GB/ document_library/Public_statement/2012).

\section{Kava}

A prominent example of severe hepatotoxicity from a herbal drug is Kava-associated liver injury. While Kava root (Piper methysticum rhizoma) has long been used as a traditional psychotropic remedy in Hawaii, Polynesia and the Fiji Islands, Kava-containing preparations are marketed in industrialized countries for the treatment of anxiety disorders and depression. Sedative activity is due to kavapyrones, including kavain, dihydrokavain, methysticin, dihydromethysticin, which act via inhibitory gammaamino-butyric acid receptor in the reticular formation and the limbic system (Davies et al. 1992; Jussofie et al. 1994). Scientific evidence supporting its anxiolytic and antidepressive efficacy is relatively good compared with other herbals as shown by a recent systematic review and metaanalysis of randomized, controlled trials with Kava for the treatment of anxiety (Pittler and Ernst 2000). A detailed analysis of 29 cases of adverse hepatic reactions due to Kava in Germany using a clinical causality score reported liver injury with both alcoholic and acetonic Kava extracts (Stickel et al. 2003). The large majority of patients were females who developed cytolytic or cholestatic hepatitis, and nine patients developed fulminant liver failure with subsequent liver transplantation in eight of the patients. Three patients died, two following unsuccessful liver transplantation. The remaining patients all recovered completely after the withdrawal of Kava. Until recently, more than 100 cases of liver damage have now been associated with Kava worldwide which is comparable with numbers that have led to the banning of synthetic drugs. The mechanism by which liver injury is precipitated is still unclear since no dose-response pattern can be recognized. However, some patients took doses exceeding several times the recommended daily dose of $120 \mathrm{mg}$. For most other patients, both the cumulative dose and the latency until the hepatotoxic reaction emerged were highly variable suggesting drug idiosyncrasy. Along this line, a poor metabolizer phenotype of cytochrome P450 2D6 was suggested as a risk factor for developing Kava-related liver damage (Russmann et al. 2001). Another possible basis for its toxicity relates to the mode of Kava extraction, with recent in vitro and animal studies confirming that aqueous kava extracts are less cytotoxic than organic solvent fractions (Jhoo et al. 2006; Sorrentino et al. 2006). It also had been speculated that Kava had been safely used in its tradition way, while toxicity had only been observed with commercial products, but acute hepatocellular injury has also been described in association with traditional use (Russmann et al. 2003; Christl et al. 2009). Nevertheless, accounting for the reports of liver damage by Kava products, the approval to distribute Kava products was withdrawn in the USA, Europe, and Australia (Centers for Disease Control and Prevention 2003).

\section{Black cohosh (Actaea racemosa; formerly Cimifuga} racemosa)

Black cohosh is a popular herbal from North America frequently used for the treatment of menopausal symptoms although its efficacy is not well demonstrated (Leach et al. 
2012). A number of reports on liver injury in Australia and North America described a wide range of liver injury ranging from mild serum aminotransferase elevations to several cases of fulminant hepatic failure leading to liver transplantation (Whiting et al. 2002; Levitsky et al. 2005; Pierard et al. 2009; Lim et al. 2013). Some patients present with features resembling autoimmune hepatitis such as elevated autoantibodies or skin rashes. In response to these reports, the Dietary Supplement Information Expert Committee of the US Pharmacopeia's Council of Experts analyzed information from human clinical case reports, adverse event reports, animal pharmacological and toxicological data, historical use, regulatory status, and contemporaneous extent of use associated with black cohosh (Mahady 2008). All 30 individual reports of liver damage available to that time were received levels of causality of "possible," but none were labeled "probable" or "certain." Based on these results, it was concluded that black cohosh products should be labeled with a cautionary statement indicating that hepatotoxicity is a possible adverse outcome. How toxicity may occur is not fully elucidated, but experimental data are suggestive of mitochondrial damage and subsequent apoptosis (Lüde et al. 2007).

\section{Miscellaneous}

Various other botanicals have been associated with toxic liver damage such as Senna (Cassia angustifolia), which is used as a laxative. Since the first case in a woman who developed relatively benign hepatitis taking approximately ten times the recommended dose with positive rechallenge (Beuers et al. 1992), two more incidents were published which showed portal vein thrombosis in one (Soyuncu et al. 2008), and acute liver failure in another case (Vanderperren et al. 2005). However, in all cases, long-term consumption of either self-manufactured or high doses of Senna was recorded.

Nadir et al. (2000) have described a man in whom shortterm use of a commercial Cascara sagrada product caused cholestatic hepatitis with subsequent portal hypertension, prolonged prothrombin time, and ascites. Cascara sagrada contains anthraquinone glycosides and is recognized as an effective laxative. Further laboratory tests revealed elevated antinuclear and antismooth muscle antibody titers of 1:640 and 1:40, respectively, and a liver biopsy showed an eosinophilic infiltrate suggesting drug-induced autoimmunity.

Another combination of herbal ingredients, known as "Prostata," was suspected to have caused cholestatic hepatitis in a man using this medication for the treatment of benign prostatic hyperplasia (Hamid et al. 1997). The presumed active ingredient Serrenoa serrulata exerts estrogenic and antiandrogenic effects, and either hormone may cause liver injury under certain circumstances.
In Ayurvedic medicine, the herbal Centella asiatica is named Gotu Kola and has been used as a psychophysical regenerator and "blood purifier," and for a plethora of indications comprising dementia, diabetic microangiopathy, skin defects, and obesity (Brinkhaus et al. 2000). Recently, three female patients who took this herbal for periods of between 1 and 6 months to lose weight, developed severe hepatic injury, including granulomatous hepatitis and cirrhosis (Jorge and Jorge 2005). Unintentional re-exposure resulted in accelerated recurrence of hepatic lesions in two of the patients and treatment with ursodeoxycholic acid at $10 \mathrm{mg} / \mathrm{kg} /$ day led to normalization of altered liver biochemistries in all three patients. Further cases have been described, even in children (Dantuluri et al. 2011; Chitturi and Farrell 2008). Extracts of this herb contain pentacyclic triterpenic saponosides including asiaticoside, madecassoside, and centellasaponins. The mechanism by which liver damage is precipitated is uncertain.

Noni juice (Morinda citrifolia) has been associated with possible liver toxicity in a case series of seven patients, among which one patients developed fulminant hepatic failure leading to liver (Stadlbauer et al. 2008; Yu et al. 2011). In the less severe cases, liver tests rapidly returned to normal after the termination of Noni intake. Since these incidents, additional cases were reported (Waldman and Piotrowicz 2013; Mrzljak et al. 2013). Active components within Noni extracts include flavonoids, glycosides, vitamins, polyunsaturated fatty acids, and anthraquinones. Which and how components within Noni cause liver injury is unknown.

Glucosamine/chondroitine preparations easily obtained over the counter are popular dietary supplements used for osteoarthritis and distributed as tablets, capsules, powder, or liquid. Rare cases of acute, mainly hepatocellular injury, sometimes mimicking (seronegative) autoimmune hepatitis have been reported in patients receiving either glucosamine alone or in combination with chondroitine sulfate (Cerda et al. 2013; von Felden et al. 2013). Causality assessment to intake of glucosamine or the combination with chondroitine sulfate, although confounded by intake of other drugs or herbals, varied between possible to probable.

\section{Herbal dietary supplements associated with liver injury}

\section{Green tea (Camellia sinensis)}

Green tea has been consumed for centuries and is currently among the most popular drinks in the world. After the first report on liver injury following the ingestion of green tea preparations in 1999 (Stickel et al. 2011), more than 60 case reports of hepatotoxicity associated with the consumption of green tea extracts, powdered leaves, green tea 
infusions, and hydroalcoholic and aqueous extracts have been recorded (Patel et al. 2013; Weinstein et al. 2012). The US Pharmacopeia systematically reviewed a subset of cases from North America, Great Britain, and Australia published until 2008 of liver injury following the ingestion of various different green tea preparations (Sarma et al. 2008). Among thirty-four evaluated cases including one lethal case, seven reports pertaining to liver damage were labeled as "probably," and the remaining seven cases as "possibly" linked to green tea. Liver histology revealed severe necro-inflammation and biliary injury. However, caution is advised about blaming liver injury on the green tea alone in some of the reported cases; since in many instances, the patients also took other products that have been implicated in causing hepatotoxicity such as Cassia angustifolia (see above), Hydroxycut, usnic acid (Yellapu et al. 2011), and Ephedra sinica (for all, see below). The background of toxicity caused by green tea is uncertain but could relate to (-)-epigallocatechin gallate (EGCG) or its metabolite (-)-epicatechin gallate (ECG) which, under certain conditions such as fasting, can induce oxidative stress and thus liver damage (Galati et al. 2006). In contrast, however, is that in vitro and in vivo experimental studies have also demonstrated hepatoprotective properties for green teas (Lin et al. 2009; Zhong et al. 2003), and a recent systematic review of clinical studies aimed at defining the therapeutic effects of $C$. sinensis in humans found overall favorable effects from the tea as reflected by reduced mortality, attenuated steatosis, and a reduced incidence of primary liver cancer (Jin et al. 2008). Structured causality assessment suggests a causal relationship between intake of green tea-containing products and liver injury, but whether the risks from green tea consumption outweigh their benefits remains unresolved so far.

\section{Herbalife}

Herbalife ${ }^{\mathrm{TM}}$ is a US-based company with an annual turnover of 4.825 billion \$ which distributes numerous products for weight control, dietary supplements, and cosmetics through online marketing and independent sales persons. Altogether, there are seven published reports describing 54 cases from Switzerland, Israel, Spain, Argentina, and Iceland of significant liver injury following consumption of Herbalife ${ }^{\mathrm{TM}}$ HDS (Elinav et al. 2007; Schoepfer et al. 2007; Duque et al. 2007; Chao et al. 2008; Stickel et al. 2009; Johannsson et al. 2010; Manso et al. 2011). The patterns of injury were mostly hepatocellular, but cases with mixed and cholestatic enzyme patterns were also observed. Severity varied from mild to severe acute and chronic liver damage including cirrhosis and acute liver failure requiring liver transplantation. Generally accepted drug-induced liver injury (DILI) assessment scoring systems were used in evaluating most of the cases, seven of whom were considered "certain" because of a positive re-challenge, while most of the remaining cases were scored as "probable." Identification of the mechanism by which liver injury was caused is notoriously difficult since the majority of patients took up to 17 different Herbalife ${ }^{\circledR}$ products at the same time. In addition to the possibility that autoimmune mechanisms played a role in inducing the liver injury among those who had elevated titers of autoantibodies and plasma cell infiltrates in their liver biopsies, adulteration of individual batches with bacterial pathogens may explain some other cases in view of a report that two patients were found to have bacterial contamination of several Herbalife ${ }^{\circledR}$ products with Bacillus subtilis and Bacillus cereus (Stickel et al. 2009). The sporadic presentation of Herbalife reported that hepatotoxicity requires an explanation. Herbalife ${ }^{\circledR}$ runs numerous production sites worldwide. Spoiled products may have been contaminated with certain germs or chemicals such as softeners, preservatives, flavor enhancers, pesticides, or heavy metals added either during the manufacturing process or by using unrefined raw products, i.e., herb extracts. These could have been responsible for local series of cases of hepatotoxicity and batch-to-batch variation. Interestingly and so far, no further cases have been observed after the latest series from Spain in 2011 (Manso et al. 2011).

\section{Usnic acid}

Usnic acid extracted from lichens and fungi have been marketed as HDS in the USA to aid in weight loss. Efficacy for this indication was postulated based on its function as an uncoupler of the respiratory chain. Uncouplers of mitochondrial oxidative phosphorylation have gained attention as possible ingredients for weight loss supplements because they are believed to increase metabolic rates and stimulated fuel oxidation which in principle can augment weight loss (Moreira et al. 2013). However, it may also cause mitochondrial injury and subsequent hepatocyte death (Han et al. 2004). Several cases of acute liver failure have been reported requiring liver transplantation following the intake of LipoKinetix ${ }^{\circledR}$, a product containing norephedrine (also known as phenylpropanolamine or PPA), caffeine, yohimbine, diiodothyronine, and sodium usniate (usnic acid), and sold as HDS capsules (Favreau et al. 2002; Durazo et al. 2004; Sanchez et al. 2006). Liver injury usually commenced acutely within the first 3 months of intake and showed a hepatocellular pattern with massive elevations of ALT and AST levels. None of the ingredients were previously associated with liver damage, and inadvertent contamination was excluded. As a consequence, the US FDA issued a warning about LipoKinetix in 2001 (Jin et al. 2008), and the product was withdrawn from the market. 


\section{Hydroxycut}

Another panel of commercial HDS product associated with liver injury, including cases with acute hepatic failure and subsequent liver transplantation, were several Hydroxycut $^{\circledR}$ products containing Garcinia cambogia, Gymnema sylvestre, chromium polynicotinate, caffeine, and green tea (Steven et al. 2005; Jones and Andrews 2007; Dara et al. 2008; Shim and Saab 2009; Fong et al. 2010). Hydroxycut preparations were sold to support weight loss and muscle built-up by conventional retailers, via internet sources, and by direct television marketing. The clinical presentation characteristically shows an acute onset after weeks of intake, presenting with high levels of serum transaminase values in most cases, while others presented more insidiously with cholestasis. Following a warning posted by the FDA in May 2009, products HDS associated with DILI were withdrawn by the manufacturer in 2009 (http://www. fda.gov/Safety/recalls/ucm/1451).

\section{Anabolic steroids}

Anabolic steroids are somehow different from the HDS described above as they are classified as class III substances, strictly regulated, and banned from amateur and professional sports activities. However, anabolics steroids are used by recreational or professional bodybuilders to improve fitness, to trim their muscle built-up, and to increase their exercise performance, often via obscure sources. Hepatotoxicity is well described, and patterns of injury include cholestasis, hepatitis, hepatocellular adenoma and even hepatocellular carcinoma, and a rare pathological entity termed peliosis hepatis characterized by the appearance of multiple cyst-like, blood-filled cavities within the liver (Ishak 1981; Erlinger 1997).

The most frequently seen injury, however, is cholestatic liver injury, often after the anabolic steroid has been stopped (Shah et al. 2008). Sometimes multi-ingredient HDS contain anabolic steroids sufficient to precipitate even severe liver injury (Kafrouni et al. 2007; Krishnan et al. 2009). The precise mechanism of toxicity is yet unclear, but findings from genotyping of patients who developed cholestasis after taking anabolic steroids suggest that anabolic steroids may cause inhibition of biliary transporter proteins such as ATP8B1/ABCB11, thereby triggering initial episodes of benign recurrent intrahepatic cholestasis (BRIC) type 1/or 2 (El Sherrif et al. 2013).

A recent case control study from Brazil suggested that anabolic steroids could be a cause of toxicant-associated non-alcoholic fatty liver disease (TAFLD). In $12.6 \%$ of subjects consuming anabolic steroids, criteria compatible with TAFLD such as steatosis on ultrasound imaging, elevated serum transaminases, and exclusion of relevant alcohol intake concomitant medication, and overweight or insulin resistance, were found. In contrast, $2.4 \%$ of bodybuilders not using anabolic steroids showed clinical signs and findings suggestive of NAFLD (Schwingel et al. 2011).

\section{1,3-Dimethylamylamine (DMAA) and OxyELITE}

OxyELITE Pro, advertised for weight loss and muscle building, is a multi-ingredient HDS previously implicated in sudden cardiac death. DMAA is a common additive in over 20 popular supplements advertised for body building and weight loss and believed to accelerate some partially defined metabolic processes. In 2013, the US Centers for Disease Control reported the results of a serious outbreak of liver injury verified in 29 patients from Hawai, using OxyELITE Pro (Centers for Disease Control and Prevention 2013). Twelve patients (41\%) used only OxyELITE Pro, while 14 subjects used one or more dietary supplements as well. Four additional cases were afterward discovered through the US public health service, and seven further cases were reported in military personnel (Foley et al. 2014; Roytman et al. 2014). One patient died, and four patients underwent liver transplantation. Consequently, preparations containing DMAA have been banned in the US.

\section{Conclusion}

The use of HDS is extensive and is largely uncontrolled neither by pharmacovigilance authorities nor by health practitioners. Doctors are often confronted with an astonishing persuasion that HDS products must be effective and safe because they are "pure" and "natural." This prevailing belief is fueled by the often long-lasting tradition of herbals in cultures with an apparently more humane view on health and well-being than modern Western societies. However, much of that is wishful thinking and rather reflects the deep desire of consumers to avoid some of the associated adverse effects Western medicine undoubtedly has. As compared to conventional pharmacologic agents, safety and efficacy of most HDS have not been rigorously tested, and some of them are less safe or even hazardous. Thus, interrogating patients about their use is an essential diagnostic component when liver injury is suspected.

Conflict of interest None declared.

\section{References}

Agarwal R, Wang ZY, Bik DP, Mukhtar H (1991) Nordihydroguaiaretic acid, an inhibitor of lipoxygenase, also inhibits cytochrome 
P-450-mediated monooxygenase activity in rat epidermal and hepatic microsomes. Drug Metab Dispos 19:620-624

Aithal GP, Rawlins MD, Day CP (2000) Clinical diagnostic scale: a useful tool in the evaluation of suspected hepatotoxic adverse drug reactions. J Hepatol 33:949-952

Alaerts G, Pieters S, Logie H et al (2014) Exploration and classification of chromatographic fingerprints as additional tool for identification and quality control of several Artemisia species. J Pharm Biomed Anal 95:34-46

Anderson IB, Mullen WH, Meeker JE, Khojasteh-Bakht SC, Oishi S, Nelson SD, Blanc PD (1996) Pennyroyal toxicity: measurement of toxic metabolite levels in two cases and review of the literature. Ann Intern Med 124:726-734

Bajaj J, Knox JF, Komorowski R, Saeian K (2003) The irony of herbal hepatitis: Ma-Huang-induced hepatotoxicity associated with compound heterozygosity for hereditary hemochromatosis. Dig Dis Sci 48:1925-1928

Bakerink JA, Gospe SM, Dimand RJ, Eldridge MW (1996) Multiple organ failure after ingestion of pennyroyal oil from herbal tea in two infants. Pediatrics 98:944-947

Benninger J, Schneider HT, Schuppan D, Kirchner T, Hahn EG (1999) Acute hepatitis induced by greater celandine (Chelidonium majus). Gastroenterology 117:1234-1237

Beuers U, Spengler U, Pape G (1992) Hepatitis after chronic abuse of senna. Lancet 337:372-373

Bouziri A, Hamdi A, Menif K, Ben Jaballah N (2010) Hepatorenal injury induced by cutaneous application of Atractylis gummifera L. Clin Toxicol (Phila) 48:752-754

Bras G, Jeliffe DB, Stuart KL (1954) Veno-occlusive disease of the liver with non-portal type of cirrhosis occurring in Jamaica. Arch Pathol 57:285

Brinkhaus B, Lindner M, Schuppan D, Hahn EG (2000) Chemical, pharmacological and clinical profile of the East Asian plant Centella asiatica. Phytomedicine 7:427-448

But PP, Tomlinson B, Lee KL (1996) Hepatitis related to the Chinese medicine Shou-wu-pian manufactured from Polygonum multiflorum. Vet Hum Toxicol 38:280-282

Cárdenas A, Restrepo JC, Sierra F et al (2006) Acute hepatitis due to Shen-Min, a herbal product derived from Polygonum multiflorum. J Clin Gastroenterol 40:629-632

Centers for Disease Control and Prevention (2003) Hepatic toxicity possibly associated with kava-containing products-United States, Germany, and Switzerland. JAMA 289:36-37

Centers for Disease Control and Prevention (2013) (CDC). Notes from the field: acute hepatitis and liver failure following the use of a dietary supplement intended for weight loss or muscle building-May-October 2013. MMWR Morb Mortal Wkly Rep 62:817-819

Cerda C, Bruguera M, Parés A (2013) Hepatotoxicity associated with glucosamine and chondroitin sulfate in patients with chronic liver disease. World J Gastroenterol 19:5381-5384

Chalasani N, Fontana RJ, Bonkovsky HL et al (2008) Causes, clinical features, and outcomes from a prospective study of druginduced liver injury in the United States. Gastroenterology 135:1924-1934

Chang J (1999) Scientific evaluation of traditional Chinese medicine under DSHEA: a conundrum. Dietary Supplement Health and Education Act. J Altern Complement Med 5:181-189

Chao S, Anders M, Turbay M, Olaiz E, Mc Cormack L, Mastai R (2008) Toxic hepatitis by consumption Herbalife products a case report. Acta Gastroenterol Latinoam 38:274-277

Chitturi S, Farrell GC (2008) Hepatotoxic slimming aids and other herbal hepatotoxins. J Gastroenterol Hepatol 23:366-373

Christl SU, Seifert A, Seeler D (2009) Toxic hepatitis after consumption of traditional kava preparation. J Travel Med 16:55-56
Crijns AP, de Smet PA, van den Heuvel M, Schot BW, Haagsma EB (2002) Acute hepatitis after use of a herbal preparation with greater celandine (Chelidonium majus). Ned Tijdschr Geneeskd 146:124-128

Dantuluri S, North-Lewis P, Karthik SV (2011) Gotu Kola induced hepatotoxicity in a child—need for caution with alternative remedies. Dig Liver Dis 43:500

Dara L, Hewett J, Lim JK (2008) Hydroxycut hepatotoxicity: a case series and review of liver toxicity from herbal weight loss supplements. World J Gastroenterol 14:6999-7004

Davies LP, Drew CA, Duffield P, Johnston GA, Jamieson DD (1992) Kavapyrones and resin: studies on GABAA, GABAB and benzodiazepine binding sites in rodent brain. Pharmacol Toxicol $71: 120-126$

Deconinck E, Custers D, De Beer JO (2015) Identification of (antioxidative) plants in herbal pharmaceutical preparations and dietary supplements. Methods Mol Biol 1208:181-199

DeLeve LD, McCuskey RS, Wang X et al (1999) Characterization of a reproducible rat model of hepatic veno-occlusive disease. Hepatology 29:1779-1791

DeLeve LD, Shulman HM, McDonald GB (2002) Toxic injury to hepatic sinusoids: sinusoidal obstruction syndrome (venoocclusive disease). Semin Liver Dis 22:27-42

Dong H, Slain D, Cheng J, Ma W, Liang W (2014) Eighteen cases of liver injury following ingestion of Polygonum multiflorum. Complement Ther Med 22:70-74

Duque JM, Ferreiro J, Salgueiro E, Manso G (2007) Hepatotoxicity associated with the consumption of herbal slimming products. Med Clin (Barc) 128:238-239

Durazo FA, Lassman C, Han SB et al (2004) Fulminant liver failure due to usnic acid for weight loss. Am J Gastroenterol 99:950-952

Eardley S, Bishop FL, Prescott P et al (2012) A systematic literature review of complementary and alternative medicine prevalence in EU. Forsch Komplementmed 19(Suppl 2):18-28

Efferth T, Kaina B (2011) Toxicities by herbal medicines with emphasis to traditional Chinese medicine. Curr Drug Metab 12:989-996

Eisenberg DM, Kessler RC, Foster C et al (1993) Unconventional medicine in the United States: prevalence, costs, and patterns of use. NEJM 328:246-252

Eisenberg DM, Davis RB, Ettner SL et al (1998) Trends in alternative medicine use in the United States, 1990-1997: results of a follow-up national study. JAMA 280:1569-1575

El Sherrif Y, Potts JR, Howard MR et al (2013) Hepatotoxicity from anabolic androgenic steroids marketed as dietary supplements: contribution from ATP8B1/ABCB11 mutations? Liver Int 33:1266-1270

Elinav E, Pinsker G, Safadi R et al (2007) Association between consumption of Herbalife ${ }^{\circledR}$ nutritional supplements and acute hepatotoxicity. J Hepatol 47:514-520

Erlinger S (1997) Drug-induced cholestasis. J Hepatol 26(Suppl 1): $1-4$

Ernst E, Hung SK (2011) Great expectations: what do patients using complementary and alternative medicine hope for? Patient 4:89-101

Estes JD, Stolpman D, Olyaei A et al (2003) High prevalence of potentially hepatotoxic herbal supplement use in patients with fulminant hepatic failure. Arch Surg 138:852-858

Fau D, Lekehal M, Farrell G et al (1997) Diterpenoids from germander, an herbal medicine, induce apoptosis in isolated rat hepatocytes. Gastroenterology 113:1334-1346

Favreau JT, Ryu ML, Braunstein G et al (2002) Severe hepatotoxicity associated with the dietary supplement LipoKinetix. Ann Intern Med 136:590-595 
Foley S, Butlin E, Shields W, Lacey B (2014) Experience with OxyELITE pro and acute liver injury in active duty service members. Dig Dis Sci 59:3117-3121

Fong T, Klontz KC, Canas-Coto A et al (2010) Hepatotoxicity due to Hydroxycut: a case series. Am J Gastroenterol 105:1561-1566

Fu PP, Chiang HM, Xia Q et al (2009) Quality assurance and safety of herbal dietary supplements. J Environ Sci Health C Environ Carcinog Ecotoxicol Rev 27:91-119

Galati G, Lin A, Sultan AM, O'Brien PJ (2006) Cellular and in vivo hepatotoxicity caused by green tea phenolic acids and catechins. Free Radic Biol Med 40:570-580

García-Cortés M, Borraz Y, Lucena MI et al (2008) Liver injury induced by "natural remedies": an analysis of cases submitted to the Spanish Liver Toxicity Registry. Rev Esp Enferm Dig 100:688-695

Georgiou M, Sianidou L, Hatzis T, Papadatos J, Koutselinis A (1988) Hepatotoxicity due to Atractylis gummifera-L. J Toxicol Clin Toxicol 26:487-493

Goodarzi M, Russell PJ, Vander Heyden Y (2013) Similarity analyses of chromatographic herbal fingerprints: a review. Anal Chim Acta 804:16-28

Gordon WP, Huitric AC, Seth CL, McClanahan RH, Nelson SD (1987) The metabolism of the abortifacient terpene, (R)-(+)pulegone, to a proximate toxin, menthofuran. Drug Metab Dispos 15:589-594

Gori L, Galluzzi P, Mascherini V et al (2011) Two contemporary cases of hepatitis associated with Teucrium chamaedrys $L$. decoction use: case reports and review of literature. Basic Clin Pharmacol Toxicol 109:521-526

Hamid S, Rojter S, Vierling J (1997) Protracted cholestatic hepatitis after the use of prostata. Ann Intern Med 127:169

Hamouda C, Hédhili A, Ben Salah N, Zhioua M, Amamou M (2004) A review of acute poisoning from Atractylis gummifera $\mathrm{L}$. Vet Hum Toxicol 46:144-146

Han D, Matsumaru K, Rettori D, Kaplowitz N (2004) Usnic acidinduced necrosis of cultured mouse hepatocytes: inhibition of mitochondrial function and oxidative stress. Biochem Pharmacol 67:439-451

Hardeman E, Van Overbeke L, Ilegems S, Ferrante M (2008) Acute hepatitis induced by greater celandine (Chelidonium majus). Acta Gastroenterol Belg 71:281-282

Horowitz RS, Feldhaus K, Dart RC, Stermitz FR, Beck JJ (1996) The clinical spectrum of Jin Bu Huan toxicity. Arch Intern Med 156:899-903

http://www.ema.europa.eu/docs/en_GB/document_library/Public_ statement/2012/01/WC500120714.pdf. Accessed Dec 222014

http://www.fda.gov/Safety/MedWatch/SafetyInformation/SafetyAlertsforHumanMedicalProducts/ucm172824.htm. Accessed Dec 222014

http://www.fda.gov/Safety/recalls/ucm145164.htm. Accessed Nov 27 2014

http://livertox.nih.gov/. Accessed Dec 222014

Ishak KG (1981) Hepatic lesions caused by anabolic and contraceptive steroids. Semin Liver Dis 1:116-128

Jang JS, Seo EG, Han C et al (2008) Four cases of toxic liver injury associated with Dictamnus dasycarpus. Korean J Hepatol 14:206-212

Jhoo J-W, Freeman JP, Heinze TM et al (2006) In vitro cytotoxocity of nonpolar constituents from different parts of kava plant (Piper methysticum). J Agric Food Chem 54:3157-3162

Jin X, Zheng RH, Li YM (2008) Green tea consumption and liver disease: a systematic review. Liver Int 28:990-996

Johannsson M, Ormarsdottir S, Olafsson S (2010) Hepatotoxicity associated with the use of Herbalife. Laeknabladid 96:167-172

Jones FP, Andrews AH (2007) Acute liver injury associated with the herbal supplement Hydroxycut in a soldier deployed to Iraq. Am J Gastroenterol 102:2357
Jorge OA, Jorge AD (2005) Hepatotoxicity associated with the ingestion of Centella asiatica. Rev Esp Enferm Dig 97:115-124

Jung KA, Min HJ, Yoo SS et al (2011) Drug-induced liver injury: twenty five cases of acute hepatitis following ingestion of Polygonum multiflorum Thunb. Gut Liver 5:493-499

Jussofie A, Schmiz A, Hiemke C (1994) Kavapyrone enriched extract from piper methysticum as modulator of the GABA binding site in different regions of rat brain. Psychopharmacol 116:469-474

Kafrouni MI, Anders RA, Verma S (2007) Hepatotoxicity associated with dietary supplements containing anabolic steroids. Clin Gastro Hepatol 5:809-812

Kakar F, Akbarian Z, Leslie T et al (2010) An outbreak of hepatic veno-occlusive disease in Western Afghanistan associate with exposure to wheat flour contaminated with pyrrolizidine alkaloids. J Toxicol 2010:313280

Kane JA, Kane SP, Jain S (1995) Hepatitis induced by traditional Chinese herbs; possible toxic components. Gut 36:146-147

Kassler WJ, Blanc P, Greenblatt R (1991) The use of medicinal herbs by human immunodeficiency virus-infected patients. Arch Intern Med 151:2281-2288

Kauma H, Koskela R, Mäkisalo H, Autio-Harmainen H, Lehtola J, Höckerstedt K (2004) Toxic acute hepatitis and hepatic fibrosis after consumption of chaparral tablets. Scand J Gastroenterol 39:1168-1171

Kouzi SA, McMurty RJ, Nelson SD (1994) Hepatotoxicity of germander (Teucrium chamedrys L.) and one of its constituent neoclerodane diterpenes, teucrin A in the mouse. Chem Res Toxicol $7: 850-856$

Krishnan PV, Feng ZZ, Gordon SC (2009) Prolonged intrahepatic cholestasis and renal failure secondary to anabolic steroidenriched dietary supplements. J Clin Gastroenterol 43:672-675

Laird AR, Ramchandani N, deGoma EM, Avula B, Khan IA, Gesundheit N (2008) Acute hepatitis associated with the use of an herbal supplement (Polygonum multiflorum) mimicking ironoverload syndrome. J Clin Gastroenterol 42:861-862

Larrey D, Vial T, Pauwels A et al (1992) Hepatitis after Germander (Teucrium chamaedrys) adminstration: another instance of herbal medicine hepatotoxicity. Ann Intern Med 117:129-132

Leach MJ, Moore V (2012) Black cohosh (Cimicifuga spp.) for menopausal symptoms. Cochrane Database Syst Rev 12(9):CD007244

Lekehal M, Pessayre D, Lereau JM, Moulis C, Fourasté I, Fau D (1996) Hepatotoxicity of the herbal medicine, germander. Metabolic activation of its furano diterpenoids by cytochrome P450 3A depletes cytoskeleton-associated protein thiols and forms plasma membrane blebs in rat hepatocytes. Hepatology 24:212-218

Levitsky J, Alli TA, Wisecarver J, Sorrell MF (2005) Fulminant liver failure associated with the use of black cohosh. Dig Dis Sci 50:538-539

Lim TY, Considine A, Quaglia A, Shawcross DL (2013) Subacute liver failure secondary to black cohosh leading to liver transplantation. BMJ Case Rep 2013

Lin TJ, Tsai MS, Chiou NM, Deng JF, Chiu NY (2002) Hepatotoxicity caused by Breynia officinalis. Vet Hum Toxicol 44:87-88

Lin TJ, Su CC, Lan CK, Jiang DD, Tsai JL, Tsai MS (2003) Acute poisonings with Breynia officinalis-an outbreak of hepatotoxicity. J Toxicol Clin Toxicol 41:591-594

Lin BR, Yu CJ, Chen WC et al (2009) Green tea extract supplement reduces D-galactosamine-induced acute liver injury by inhibition of apoptotic and proinflammatory signaling. J Biomed Sci 16:35

Lin G, Wang JY, Li N et al (2011) Hepatic sinusoidal obstruction syndrome associated with consumption of Gynura segetum. J Hepatol 54:666-673

Loeper J, Descatoire V, Letteron P et al (1994) Hepatotoxicity of germander in mice. Gastroenterology 106:464-472 
Lüde S, Török M, Dieterle S et al (2007) Hepatic effects of Cimicifuga racemosa extract in vivo and in vitro. Cell Mol Life Sci 64:2848-2857

Ma KF, Zhang XG, Jia HY (2014) CYP1A2 polymorphism in Chinese patients with acute liver injury induced by Polygonum multiflorum. Genet Mol Res 13:5637-5643

Mahady GB, Low Dog T, Barrett ML, Chavez ML, Gardiner P, Ko R, Marles RJ, Pellicore LS, Giancaspro GI, Sarma DN (2008) United States pharmacopeia review of the black cohosh case reports of hepatotoxicity. Menopause 15:628-638

Manso G, López-Rivas L, Salgueiro ME et al (2011) Continuous reporting of new cases in Spain supports the relationship between Herbalife ${ }^{\circledR}$ products and liver injury. Pharmacoepidemiol Drug Saf 20:1080-1087

Maria VAJ, Victorino RMM (1997) Development and validation of a clinical scale for the diagnosis of drug-induced hepatitis. Hepatology 26:664-669

Marignani M, Gallina S, Di Fonzo M et al (2010) Use and safety perception of herbal remedies in patients with liver/biliary tract disorders: an Italian study. J Clin Gastroenterol 44(Suppl 1):S54-S57

Mattei A, Rucay P, Samuel D (1995) Liver transplantation for severe acute liver failure after herbal medicine (Teucrium polium) administration. J Hepatol 22:597

Mazzanti G, Battinelli L, Daniele C et al (2004) New case of acute hepatitis following the consumption of Shou Wu Pian, a Chinese herbal product derived from Polygonum multiflorum. Ann Intern Med 140:W30

McRae CA, Agarwal K, Mutimer D, Bassendine MF (2002) Hepatitis associated with Chinese herbs. Eur J Gastroenterol Hepatol 14:559-562

Mei N, Guo L, Fu PP, Fuscoe JC, Luan Y, Chen T (2010) Metabolism, genotoxicity, and carcinogenicity of comfrey. J Toxicol Environ Health B Crit Rev 13:509-526

Moreira CT, Oliveira AL, Comar JF, Peralta RM, Bracht A (2013) Harmful effects of usnic acid on hepatic metabolism. Chem Biol Interact 203:502-511

Moro PA, Cassetti F, Giugliano G et al (2009) Hepatitis from Greater celandine (Chelidonium majus L.): review of literature and report of a new case. J Ethnopharmacol 124:328-332

Mouaffak Y, Boutbaoucht M, Ejlaidi A, Toufiki R, Younous S (2013) Fatal poisoning by Atractylis gummifera L.: a case report. Arch Pediatr 20:496-498

Mrzljak A, Kosuta I, Skrtic A, Kanizaj TF, Vrhovac R (2013) Druginduced liver injury associated with Noni (Morinda citrifolia) juice and phenobarbital. Case Rep Gastroenterol 7:19-24

Nadir A, Agrawal S, King PD, Marshall JB (1996) Acute hepatitis associated with the use of a Chinese herbal product, Ma-Huang. Am J Gastrol 91:1436-1438

Nadir A, Reddy D, Van Thiel DH (2000) Cascara sagrada-induced intrahepatic cholestasis causing portal hypertension: case report and review of herbal hepatotoxicity. Am J Gastroenterol 95:3634-3637

Navarro VJ, Barnhart H, Bonkovsky HL et al (2014) Liver injury from herbals and dietary supplements in the US Drug Induced Liver Injury Network. Hepatology 60:1399-1408

Neff GW, Reddy KR, Durazo FA, Meyer D, Marrero R, Kaplowitz N (2004) Severe hepatotoxicity associated with the use of weight loss diet supplements containing ma huang or usnic acid. J Hepatol 41:1062-1064

Ng V, Tran TT, Sundaram V (2014) An unexpected cause of an infiltrative liver mass. Gastroenterology 147:e12-e13

Panis B, Wong DR, Hooymans PM et al (2005) Recurrent toxic hepatitis in a Caucasian girl related to the use of Shou-Wu-Pian, a Chinese herbal preparation. J Pediatr Gastroenterol Nutr 41:256-258
Park GJ, Mann SP, Ngu MC (2001) Acute hepatitis induced by ShouWu-Pian, a herbal product derived from Polygonum multiflorum. J Gastroenterol Hepatol 16:115-117

Patel SS, Beer S, Kearney DL, Phillips G, Carter BA (2013) Green tea extract: a potential cause of acute liver failure. World J Gastroenterol 19:5174-5177

Piciotto A, Campo N, Brizzolara R et al (1998) Chronic hepatitis induced by Jin Bu Huan. J Hepatol 28:165-167

Pierard S, Coche JC, Lanthier P et al (2009) Severe hepatitis associated with the use of black cohosh: a report of two cases and an advice for caution. Eur J Gastroenterol Hepatol 21:941-945

Pittler MH, Ernst E (2000) Efficacy of kava extract for treating anxiety: systematic review and meta-analysis. J Clin Psychopharmacol 20:84-89

Poon WT, Chau TL, Lai CK et al (2008) Hepatitis induced by Teucrium viscidum. Clin Toxicol (Phila) 46:819-822

Popat A, Shear NH, Malkiewicz I et al (2001) The toxicity of Callilepis laureola, a South African traditional herbal medicine. Clin Biochem 34:229-236

Popat A, Shear NH, Malkiewicz I, Thomson S, Neuman MG (2002) Mechanism of Impila (Callilepis laureola)-induced cytotoxicity in Hep G2 cells. Clin Biochem 35:57-64

Posadzki P, Watson LK, Alotaibi A, Ernst E (2013) Prevalence of use of complementary and alternative medicine (CAM) by patients/ consumers in the UK: systematic review of surveys. Clin Med 13:126-131

Prakash AS, Pereira TN, Reilly PE, Seawright AA (1999) Pyrrolizidine alkaloids in human diet. Mutat Res 443:53-67

Regev A (2014) Drug-induced liver injury and drug development: industry perspective. Semin Liver Dis 34:227-239

Robinson O, Want E, Coen M et al (2014) Hirmi valley liver disease: a disease associated with exposure to pyrrolizidine alkaloids and DDT. J Hepatol 60:96-102

Rochon J, Protiva P, Seeff LB et al (2008) Drug-induced Liver Injury Network (DILIN): reliability of the Roussel Uclaf causality assessment method for assessing causality in drug-induced liver injury. Hepatology 48:1175-1182

Roytman MM, Pörzgen P, Lee CL et al (2014) Outbreak of severe hepatitis linked to weight-loss supplement OxyELITE Pro. Am J Gastroenterol 109:1296-1298

Russmann S, Lauterburg BH, Helbling A (2001) Kava hepatotoxicity. Ann Intern Med 135:68-69

Russmann S, Barguil Y, Cabalion P et al (2003) Hepatic injury due to traditional aqueous extracts of kava root in New Caledonia. Eur J Gastroenterol Hepatol 15:1033-1036

Sanchez W, Maple JT, Burgart LJ, Kamath PS (2006) Severe hepatotoxicity associated with use of a dietary supplement containing usnic acid. Mayo Clin Proc 81:541-544

Sarma DN, Barrett ML, Chavez ML et al (2008) Safety of green tea extracts. A systematic review by the US pharmacopeia. Drug Saf 31:469-484

Savvidou S, Goulis J, Giavazis I, Patsiaoura K, Hytiroglou P, Arvanitakis C (2007) Herb-induced hepatitis by Teucrium polium L.: report of two cases and review of the literature. Eur J Gastroenterol Hepatol 19:507-511

Schoepfer AM, Engel A, Fattinger K et al (2007) Herbal does not mean innocuous: 10 cases of severe hepatotoxicity associated with dietary supplements from Herbalife ${ }^{\circledR}$ products. J Hepatol 47:521-526

Schwingel PA, Cotrim HP, Salles BR et al (2011) Anabolic-androgenic steroids: a possible new risk factor of toxicant-associated fatty liver disease. Liver Int 31:348-353

Seeff LB, Bonkovsky HL, Navarro VJ, Wang G (2014) Herbals and the liver-a review of adverse effects and mechanisms. Gastroenterology. doi:10.1053/j.gastro.2014.12.004 
Shah NL, Zacharias I, Khettry U, Afdhal N, Gordon FD (2008) Methasteron-associated cholestatic liver injury: clinicopathologic findings in 5 cases. Clin Gastro Hepatol 6:255-258

Sheikh NM, Philen RM, Love LA (1997) Chaparral-associated Hepatotoxicity. Arch Intern Med 157:913-919

Shim M, Saab S (2009) Severe hepatotoxicity due to Hydroxycut: a case report. Dig Dis Sci 54:406-408

Sorrentino L, Capasso A, Schmidt M (2006) Safety of ethanolic kava extract: results of a study of chronic toxicity in rats. Phytomedicine 13:542-549

Soyuncu S, Cete Y, Nokay AE (2008) Portal vein thrombosis related to Cassia angustifolia. Clin Toxicol (Phila) 46:774-777

Sperl W, Stuppner H, Gassner I, Judmaier W, Dietze O, Vogel W (1995) Reversible hepatic veno-occlusive disease in an infant after consumption of pyrrolizidine-containing herbal tea. Eur J Pediatr 154:112-116

Stadlbauer V, Weiss S, Payer F, Stauber RE (2008) Herbal does not at all mean innocuous: the sixth case of hepatotoxicity associated with Morinda citrifolia (noni). Am J Gastroenterol 103:2406-2407

Steven T, Qadri A, Zein NN (2005) Two patients with acute liver injury associated with the use of the herbal weight-loss supplement Hydroxycut. Ann Intern Med 142:477-478

Stewart MJ, Steenkamp V, van der Merwe S, Zuckerman M, Crowther NJ (2002) The cytotoxic effects of a traditional Zulu remedy, impila (Callilepis laureola). Hum Exp Toxicol 21:643-647

Stickel F, Pöschl G, Seitz HK et al (2003a) Acute hepatitis induced by Greater Celandine (Chelidonium majus). Scand J Gastroenterol 38:565-568

Stickel F, Baumüller HM, Seitz KH et al (2003b) Hepatitis induced by Kava-Kava (Piper methysticum rhizoma). J Hepatol 39:62-67

Stickel F, Droz S, Patsenker E, Boegli-Studer K, Aebi B, Leib SL (2009) Severe hepatotoxicity following ingestion of Herbalife ${ }^{\circledR}$ nutritional supplements contaminated with Bacillus subtilis. J Hepatol 50:111-117

Stickel F, Kessebohm K, Weimann R, Seitz HK (2011) Review of liver injury associated with dietary supplements. Liver Int 31:595-605

Stillman AE, Huxtable RJ, Consroe P, Kohnen P, Smith S (1977) Hepatic veno-occlusive disease due to pyrrolizidine (Senecio) poisoning in Arizona. Gastroenterology 73:349-352

Strader DB, Bacon BR, Lindsay KL et al (2002) Use of complementary and alternative medicine in patients with liver disease. Am J Gastroenterol 97:2391-2397

Sullivan JB Jr, Rumack BH, Thomas H Jr, Peterson RG, Bryson P (1979) Pennyroyal oil poisoning and hepatotoxicity. J Am Med Assoc 242:2873-2874

Tandon BN, Tandon RK, Tandon HD, Narndranathan M, Joshi YK (1976) An epidemic of veno-occlusive disease of liver in Central India. Lancet 2:271-272

Teschke R, Wolff A, Frenzel C, Schulze J, Eickhoff A (2012) Herbal hepatotoxicity: a tabular compilation of reported cases. Liver Int 32:1543-1556

Thomassen D, Slattery JT, Nelson SD (1990) Menthofuran-dependent and independent aspects of pulegone hepatotoxicity: roles of glutathione. J Pharmacol Exp Ther 253:567-572

Thomassen D, Knebel N, Slattery J, McClanahan RH, Nelson SD (1992) Reactive intermediates in the oxidation of menthofuran by cytochromes P-450. Chem Res Toxicol 5:123-130
Vanderperren B, Rizzo M, Angenot L, Haufroid V, Jadoul M, Hantson P (2005) Acute liver failure with renal impairment related to the abuse of senna anthraquinone glycosides. Ann Pharmacother 39:1353-1357

Vigano M, Lampertico P, Colombo M (2008) Acute hepatitis following assumption of a herbal remedy. Eur J Gastroenterol Hepatol 20:364-365

Vlietinck A, Pieters L, Apers S (2009) Legal requirements for the quality of herbal substances and herbal preparations for the manufacturing of herbal medicinal products in the European Union. Planta Med 75:683-688

von Felden J, Montani M, Kessebohm K, Stickel F (2013) Druginduced acute liver injury mimicking autoimmune hepatitis after intake of dietary supplements containing glucosamine and chondroitin sulfate. Int J Clin Pharmacol Ther 51:219-223

Waldman W, Piotrowicz G, Sein Anand J (2013) Hepatoxic effect of a noni juice consumption-a case report. Przegl Lek 70:690-692

Watson AR, Coovadia HM, Bhoola KD (1979) The clinical syndrome of Impila (Callilepis laureola) poisoning in children. S Afr Med J 55:290-292

Weinstein DH, Twaddell WS, Raufman JP, Philosophe B, Mindikoglu AL (2012) SlimQuick ${ }^{\mathrm{TM}}$-associated hepatotoxicity in a woman with alpha-1 antitrypsin heterozygosity. World J Hepatol 4:154-157

Whiting PW, Clouston A, Kerlin P (2002) Black cohosh and other herbal remedies associated with acute hepatitis. Med J Aust 177:440-443

Wilmot FC, Robertson GW (1920) Senecio disease or cirrhosis of the liver due to senecio poisoning. Lancet II:828-829

Woolf GM, Petrovic LM, Roiter SE et al (1994) Acute hepatitis associated with the Chinese herbal product Jin Bu Huan. Ann Intern Med 10:729-735

Yellapu RK, Mittal V, Grewal P, Fiel M, Schiano T (2011) Acute liver failure caused by 'fat burners' and dietary supplements: a case report and literature review. Can J Gastroenterol 25:157-160

Yoshida EM, McLean CA, Cheng ES et al (1996) Chinese herbal medicine, fulminant hepatitis and liver transplantation. Am J Gastroenterol 12:2647-2648

Yu EL, Sivagnanam M, Ellis L, Huang JS (2011) Acute hepatotoxicity after ingestion of Morinda citrifolia (Noni Berry) juice in a 14-year-old boy. J Pediatr Gastroenterol Nutr 52:222-224

Zhao P, Wang C, Liu W, Wang F (2014) Acute liver failure associated with traditional Chinese medicine: report of 30 cases from seven tertiary hospitals in China. Crit Care Med 42:e296-e299

Zhong Z, Froh M, Lehnert M et al (2003) Polyphenols from Camellia sinenesis attenuate experimental cholestasis-induced liver fibrosis in rats. Am J Physiol Gastrointest Liver Physiol 285:G1004-G1013

Zhou Y, Yang L, Liao Z, He X, Zhou Y, Guo H (2013) Epidemiology of drug-induced liver injury in China: a systematic analysis of the Chinese literature including 21,789 patients. Eur J Gastroenterol Hepatol 25:825-829

Zhou H, Wang YX, Lou HY, Xu XJ, Zhang MM (2014) Hepatic sinusoidal obstruction syndrome caused by herbal medicine: CT and MRI features. Korean J Radiol 15:218-225

Zhu X, Kruhlak NL (2014) Construction and analysis of a human hepatotoxicity database suitable for QSAR modeling using post-market safety data. Toxicology 321:62-72 